\title{
Analisis Pola Waktu Mula Anomali Polarisasi Sinyal Sebelum Gempa Bumi Di Wilayah Aceh Dan Sumatera Utara
}

\author{
Fitria Dwi Andriani $^{1 \cdot *}$, Mimin Iryanti ${ }^{1}$, Indriana Lucky Sari ${ }^{2}$ \\ ${ }^{1}$ Departemen Pendidikan Fisika, Universitas Pendidikan Indonesia \\ Jl. Dr. Setiabudhi No. 299 Bandung 40154 \\ ${ }^{2}$ Badan Metorologi Klimatologi dan Geofisika, Jl. Cemara 71, Bandung \\ *Email: fdwiandriani@gmail.com
}

\begin{abstract}
ABSTRAK
Telah dilakukan penelitian mengenai pola waktu mula anomali polarisasi sinyal geomagnet yang dapat dijadikan sebagai parameter dalam menentukan tanda atau gejala sebelum gempa bumi dengan menggunakan data komponen magnetik yang diperoleh dari pengamatan geomagnetik di Obsevatorim Badan Meteorologi Klimatologi Geofisika Tungtungan. Penelitian ini bertujuan untuk mengetahui pola waktu mula anomali polarisasi sebelum gempa bumi di wilayah Aceh dan Sumatera Utara terjadi. Gempa bumi yang di invertigasi merupakan gempa bumi yang terjadi di Sumatera Utara dan Aceh pada periode 2012-2015 dan memiliki magnitude $>5 \mathrm{SR}$. Polariasi dilakukan dengan membandingkan data geomagnet komponen $\mathrm{H}$ dan Z. Transformasi fourier diperlukan untuk merubah sinyal menjadi domain frekuensi. Kemudian dilakukan penapisan frekuensi sinyal pada spektrum 0,05-0,02 Hz. Spektrum ini dipilih karena berkaitan dengan aktivitas sebelum gempa. Hasil polarisasi sinyal dibandingkan dengan data Indeks Dst untuk menentukan waktu mula anomali yang berasal dari aktivitas gempa. Selanjutnya dilakukan analisis pola waktu tehadap magnitudo gempa. Berdasarkan pola yang telah dihasilkan menggambarkan bahwa pola waktu mula anomali yang semakin lama akan menghaslkan magnitudo gempa yang lebih besar.
\end{abstract}

Kata Kunci: Anomali Polarisasi, Sinyal Geomagnet, Gempa Bumi, Indeks 


\begin{abstract}
Research on the time pattern of anomaly polarization of geomagnetic signals can be used as a parameter in determining the signs or symptons before the earthquake using magnetic component data obtained from geomagnetic observation in Observatorium Meteorology Climatology Geophysics Tungtungan. The purpose of this reseach is to know the time pattern of polarization anomaly before earthquake in Aceh and North Sumatera region. The investigated earthquake is an earthquake in the period 2012-2015. Polarization is done by comparing geomagnetic data of $\mathrm{H}$ and $\mathrm{Z}$ components. Fourier transform are needed to convert signals into frequency domains. Then performed signal frequency filtering on spectrum 0,05-0,02 Hz. this spectrum was chosen because it is related to activity before the earthquake. The result of the signal polarization is compared with the Dst Index data to determine the starting time of the anomaly derivedfrom the earthquake activity. Furthermore, the time pattern analysis was made to the anomaly starting time pattern that will prolog the magnitude of the larger earthquake.
\end{abstract}

Keywords : Polarization Anomaly, Geomagnet Signal, Earthquake, Index

\section{Pendahuluan}

Wilayah Aceh dan Sumatera Utara merupakan wilayah yang terletak di dekat perbatas dua lempeng. Kedua lempeng ini memiliki aktivitas berupa pergerakan yang berpotensi menyebabkan terjadinya tumbukan antar lempeng. Sehingga tumbukan ini menyebabkan patahan yang merupakan sumber gempa bumi. Gempa bumi merupakan fenomena getaran di permukaan bumi akibat pelepasan energi dari perut bumi yang menyebabkan suatu gelombang yang menyebar sampai ke permukaan bumi. pelepasan energi ini disebabkan oleh patahan dari tumbukan kedua lempeng. Peristiwa ini sangat merugikan banyak orang karena dapat menimbulkan munculnya korban jiwa dan kerugian materil di daerah yang mengalami peristiwa tersebut. Sehingga, perlu dilakukan pengamatan 
mengenai tanda atau gejala yang terjadi sebelum gempa bumi. Hal ini dilakukan untuk mengurangi dampak kerugian dari gempa bumi. Tanda atau gejala yang terjadi sebelum gempa dapat diamati melalui anomali emisi gelombang elektromagnetik pada spektrum sinyal geomagnetik dari dalam perut bumi sampai ke atmosfer sebelum gempa bumi. Secara fisis anomali ini disebabkan oleh perubahan sifat material didalam perut bumi akibat tekanan dan regangan yang terjadi pada masa persiapan gempa. Perubahan sifat fisis tersebut berupa perubahan sifat magnetik, radioaktivitas, resistivitas, suhu, komposisi electron dan banyak lainnya (Yumoto, dkk. 2009; Nurdiyanto, 2011).

Pada penelitian ini diterapkan prosedur polarisasi power ratio pada sinyal geomagnetik untuk menentukan pola waktu mula terjadinya anomali sebelum gempa bumi di regional Sumatera Utara dan Aceh. Sinyal geomagnet diperoleh dari data geomagnet yang direkam oleh magnetometer di Observatorium magnetik Badan Meteorologi Klimatologi dan Geofisika Tungtungan.

\section{Metode}

Pengolahan sinyal geomagnet dilakukan dengan menggunakan data variasi harian geomagnet. Data variasi harian geomagnet diperoleh dari hasil pengukuran tim BMKG Stasiun Geofisika Tungtungan di Obsevatorium Magnetik Tungtungan dengan bantuan alat Variometer fluxgate tri axial tipe LEMI-018. Pengukuran dilakukan setiap 1 jam sekali, namun dalam penelitian ini data yang diolah hanya pada rentang waktu 2012-2015 saja. Dalam menentukan pola waktu mula anomali sinyal geomagnetik dipelukan data gempa untuk studi kasus. Data gempa yang digunakan yaitu data gempa yang diperoleh dari katalog gempa BMKG serta memiliki magnitude gempa bumi >5,5 Mw dan berjarak < $550 \mathrm{~km}$ dari obsevatorium Tungtungan. Data gempa ini dijelaskan pada Tabel 1. Data variasi harian geomagnet yang diperoleh masih di pengaruhi oleh faktor global berupa aktivitas matahari dan lokal berupa aktivitas seismik sehingga untuk memisahkannya diperlukan data Indeks Dst yaitu data geomagnet yang dipengaruhi oleh faktor global saja. 
Data Indeks Dst diperoleh dari Kyoto

University.

Berdasarkan penelitian yang dilakukan oleh Prattes dkk. (2011), pengolahan sinyal dilakukan dengan mengubah data variasi harian geomagnet dari domain waktu menjadi domain frekuensi menggunakan Transformasi Fourier (Fast Fourier Transform). Hal ini dilakukan karena data geomagnet komponen $\mathrm{H}$ dan $\mathrm{Z}$ yang diperoleh masih dalam domain waktu. Data yang sudah dalam domain frekuensi kemudian di filter sesuai dengan rentang frekuensi yang diinginkan yaitu 0.05-0.02 Hz. rentang frekuensi ini dipilih karena sepktrum frekuensi tersebut berhubungan dengan aktivitas sebelum gempa (Karakelian, dkk. 2000).

Kemudian, dilakukan perhitungan spektral kerapatan daya (PSD) pada setiap komponen $\mathrm{H}$ dan $\mathrm{Z}$ yang sudah di filter menggunakan persamaan 1. Untuk memperoleh analisis statistik yang lebih baik maka dilakukan perhitungan rataan harian dari spektral kerapatan daya komponen $\mathrm{H}$ dan $\mathrm{Z}$ dengan menggunakan persamaan 2 . Kemudian, data rataan harian spektral kerapatan daya komponen $\mathrm{Z}$ dan $\mathrm{H}$ digunakan untuk menghitung rata-rata bulanan masing-masing komponen.

$$
\begin{gathered}
S_{\text {HDay }}(\omega)=\frac{\left|B_{H}(\omega)\right|}{2 \pi \cdot \Delta f} \\
S_{Z \text { Day }}(\omega)=\frac{\left|B_{Z}(\omega)\right|}{2 \pi \cdot \Delta f} \\
S_{\Sigma H \text { Day }}(\omega)=\sqrt{\frac{1}{N} \sum\left[S_{H D a y}(\omega)\right]^{2}} \\
S_{\Sigma Z \text { Day }}(\omega)=\sqrt{\frac{1}{N} \sum\left[S_{\text {ZDay }}(\omega)\right]^{2}}
\end{gathered}
$$

dengan $S_{Z \text { Day }}\left(\mathrm{nT}^{2} \mathrm{~Hz}^{-1}\right)$ dan $S_{H \text { Day }}$ $\left(\mathrm{nT}^{2} \mathrm{~Hz}^{-1}\right)$ merupakan Spektral Kerapatan Daya kompone $\mathrm{Z}$ dan komponen $\mathrm{H}$ serta $B_{Z}(\omega)$ dan $B_{H}(\omega)$ merupakan magnitude komponen $\mathrm{Z}$ dan komponen $\mathrm{H}$ pada rentang frekuensi $\Delta f . S_{\Sigma H \text { Day }}(\omega)$ dan $S_{\Sigma Z \text { Day }}(\omega)$ merupakan rataan harian PSD komponen $\mathrm{H}$ dan komponen $\mathrm{Z}$ serta $N$ merupakan jumlah data hasil filtering. Polarisasi sinyal geomagnetk dilakukan dengan cara membandingkan rata-rata harian komponen $\mathrm{Z}$ dengan rata-rata harian komponen $\mathrm{H}$ yang diperoleh persamaan 3.

$$
\begin{aligned}
& H_{\text {day }}=\frac{s_{\Sigma H \text { Day }}-\mu_{\Sigma H \text { Mounth }}}{\sigma_{\Sigma H \text { Mounth }}} \\
& Z_{\text {day }}=\frac{s_{\Sigma Z \text { Day }}-\mu_{\Sigma Z \text { Mounth }}}{\sigma_{\Sigma Z \text { Mounth }}}
\end{aligned}
$$

Dengan $H_{\text {day }}$ dan $Z_{\text {day }}$ merupakan ratarata harian geomagnet komponen $\mathrm{H}$ dan 
komponen $\mathrm{Z}$ sedangkan $\mu_{\Sigma H \text { Mounth }}$ dan $\mu_{\Sigma Z \text { Mounth }}$ merupakan rataan bulanan spektral kerapatan daya komponen $\mathrm{H}$ dan komponen Z. polarisasi sinyal direpresentasikan pada persamaan 4

$P_{\text {day }}=\frac{Z_{\text {day }}}{H_{\text {day }}}$

Tabel 1. Tabel peristiwa gempa bumi yang digunakan dalam studi kasus

(Sumber http://inatews.bmkg. go.id)

\begin{tabular}{ccccc}
\hline $\mathrm{N}$ & Waktu & $\begin{array}{c}\text { Magni } \\
\text { tude } \\
\mathrm{o}\end{array}$ & $\begin{array}{c}\text { Kedala } \\
\text { man } \\
(\mathrm{Mm})\end{array}$ & $\begin{array}{c}\text { Jarak } \\
\text { episenter } \\
(\mathrm{km})\end{array}$ \\
\hline 1 & $21 / 01 / 2013$ & 5,9 & 10 & 359,2 \\
\hline 2 & $01 / 12 / 2013$ & 5,6 & 15 & 248,53 \\
\hline 3 & $02 / 07 / 2013$ & 6,2 & 10 & 254,79 \\
\hline 4 & $01 / 05 / 2014$ & 5,7 & 58 & 194,61 \\
\hline 5 & $05 / 07 / 2014$ & 6 & 22 & 252,16 \\
\hline 6 & $27 / 01 / 2015$ & 5,6 & 25 & 291,35 \\
\hline
\end{tabular}

\section{Hasil Dan Pembahasan}

\section{Gempa Bumi 21 Januari 2013}

Gambar 1 panel 1 merupakan Indeks Dst pada November 2012-Oktober 2013 dan panel 2 merupakan hasil polarisasi sinyal geomagnetik pada November 2012-Oktober 2013 dalam rentang frekuensi 0,05-0,02 $\mathrm{Hz}$. Berdasarkan Indeks Dst, WDC-Kyoto
University pada bulan januari 2013, gangguan sinyal geomagnet dari aktivitas Matahari sangat kecil sehingga jika terjadi anomali, bukan berasal dari aktivitas global atau aktivitas badai matahari.

Waktu mula terjadinya anomali polarisasi sinyal sebelum terjadi gempa terjadi pada 12 Januari 2013 atau 9 hari sebelum gempa bumi 21 Januari 2013. Anomali ini ditunjukan dengan penurunan pola polarisasi melebihi $\mu-2 \sigma \quad$ sebelum gempa bumi terjadi yang terlihat pada Gambar 4.4 pada blok merah sebelum gempa 21 Januari 2013. Dalam arti fisis penurunan harga $\mathrm{Z} / \mathrm{H}$ menggambarkan bahwa batuan di bawah permukaan mengalami tekanan. Berdasarkan data Indeks Dst, pada saat anomali terjadi tidak terdapat adanya badai, hal ini berarti anomali yang terjadi merupakan anomali yang disebakan oleh gempa bumi 21 Januari 2013.

2. Gempa Bumi 2 Juli 2013

Berdasarkan Indeks Dst WDC-Kyoto University (gambar 1) pada bulan Juni 2013,terdapat beberapa gangguan sinyal geomagnet dari aktivitas Matahari (Indeks Dst >-50nT), 
sehingga cukup sulit dalam menentukan anomali yang berasal dari gempa bumi 2 Juli 2013. Waktu mula anomali polarisasi sinyal terjadi pada 22 Juni 2013 atau 13 hari sebelum gempa bumi 2 Juli 2014. Anomali ini ditunjukan dengan peningkatan pola polarisasi melebihi $\mu+2 \sigma$ sebelum gempa bumi terjadi yang terlihat pada Gambar 1 pada blok merah sebelum gempa 2 Juli 2013. Dalam arti fisis penurunan harga $\mathrm{Z} / \mathrm{H}$ menggambarkan bahwa batuan di bawah permukaan mengalami regangan batuan. Berdasarkan data Indeks Dst pada Gambar 1, saat anomali terjadi tidak terdapat adanya badai, hal ini berarti anomali yang terjadi merupakan anomali yang disebakan oleh gempa bumi 2 Juli 2013.

3. Gempa Bumi 1 Desember 2013 Kejadian Gempa bumi 1 Desember 2013 merupakan gempa bumi yang memiliki magnitude sebesar 5,6 SR yang terjadi di daerah Sinabang dan memiliki kedalaman yang dangkal yaitu $20 \mathrm{~km}$ dari permukaan. Gambar 2 panel 1 merupakan Indeks Dst pada November 2013-Oktober 2014 dan panel 2 merupakan hasil polarisasi sinyal geomagnetik pada November
2013-Oktober 2014 dalam rentang frekuensi 0,05-0,02 Hz. Berdasarkan Indeks Dst, WDC-Kyoto University pada bulan November 2013,terdapat gangguan sinyal geomagnet dari aktivitas Matahari (Indeks Dst >30nT), namun gangguan tersebut sangat kecil sehingga jika terjadi anomali, bukan berasal dari aktivitas global atau aktivitas badai matahari.

Waktu mula terjadinya anomali polarisasi sinyal geomagnetik terjadi pada 26 November 2013 atau 5 hari sebelum gempa bumi 1 Desember 2013. Anomali ini ditunjukan dengan peningkatan kembali pola polarisasi melebihi $\mu+2 \sigma$ sebelum gempa bumi terjadi yang terlihat pada Gambar 2 pada blok merah sebelum gempa 1 Desember 2013. Secara fisis hal ini dapat dikatakan bahwa ketika terjadi perubahan anomali komponen $\mathrm{Z} / \mathrm{H}$ menurun, batuan dibawah pemukaan sedang mengalami regangan. Berdasarkan data Indeks Dst, pada saat anomali terjadi tidak terdapat adanya badai, hal ini berarti anomali yang terjadi merupakan anomali yang disebakan oleh gempa bumi 1 Desember 2013.

4. Gempa Bumi 1 Mei 2014 
Kejadian Gempa bumi 1 Mei 2014 merupakan gempa bumi yang memiliki magnitude sebesar 5,7 SR yang terjadi di daerah Onan Ganjang dan memiliki kedalaman yang cukup dangkal yaitu 58 km dari permukaan. Berdasarkan Indeks Dst, WDC-Kyoto University pada bulan Mei 2014,terdapat beberapa gangguan sinyal geomagnet dari aktivitas Matahari (Indeks Dst >-30nT), namun gangguan tersebut sangat kecil sehingga jika terjadi anomali, bukan berasal dari aktivitas global atau aktivitas badai matahari. Waktu mulaterjadinya anomali polarisasi sinyal yaitu pada 25 April 2014 atau 7 hari sebelum gempa bumi 1 Mei 2014. Anomali ini ditunjukan dengan penurunan pola polarisasi melebihi $\mu-2 \sigma$ sebelum gempa bumi terjadi yang terlihat pada Gambar 2 pada blok merah sebelum gempa 1 Mei 2014. Dalam arti fisis penurunan harga $\mathrm{Z} / \mathrm{H}$ menggambarkan bahwa batuan di bawah permukaan mengalami regangan batuan. Berdasarkan data Indeks Dst pada Gambar 2, saat anomali terjadi tidak terdapat adanya badai, hal ini berarti anomali yang terjadi merupakan anomali yang disebakan oleh gempa bumi 1 Mei 2014.

5. Gempa Bumi 5 Juli 2014

Kejadian Gempa bumi 5 Juli 2014 merupakan gempa bumi yang memiliki magnitude sebesar 6 SR yang terjadi di daerah Sinabang dan memiliki kedalaman yang dangkal yaitu $20 \mathrm{~km}$ dari permukaan. Berdasarkan Indeks Dst, WDC-Kyoto University pada bulan Juli 2014,terdapat beberapa gangguan sinyal geomagnet dari aktivitas Matahari (Indeks Dst >-30nT), namun gangguan tersebut sangat kecil sehingga jika terjadi anomali, bukan berasal dari aktivitas global atau aktivitas badai matahari. Waktu mula terjadinya anomali polarisasi sinyal yaitu pada 26 Juni 2014 atau 9 hari sebelum gempa bumi 5 Juli 2014. Anomali ini ditunjukan dengan penurunan pola polarisasi melebihi $\mu-2 \sigma \quad$ selanjutnya terjadi peningkatan kembali pola polarisasi melebihi $\mu+2 \sigma$ sebelum gempa bumi terjadi yang terlihat pada Gambar 2 pada blok merah sebelum gempa 5 Juli 2014. Secara fisis hal ini dapat dikatakan bahwa ketika terjadi perubahan anomali komponen $\mathrm{Z} / \mathrm{H}$ 
menurun, batuan dibawah pemukaan sedang mengalami tekanan batuan dan kemudian terjadi reganagn sehingga pola anomali komponen $\mathrm{Z} / \mathrm{H}$ kembali meningkat. Berdasarkan data Indeks Dst pada Gambar 2, saat anomali terjadi tidak terdapat adanya badai, hal ini berarti anomali yang terjadi merupakan anomali yang disebakan oleh gempa bumi 5 Juli 2014.

6. Gempa Bumi 27 Januari 2015

Kejadian Gempa bumi 27 Januari 2015 merupakan gempa bumi yang memiliki magnitude sebesar 5,7 SR yang terjadi di daerah Sinabang dan memiliki kedalaman yang cukup dangkal yaitu $25 \mathrm{~km}$ dari permukaan. Gambar 4.3 panel 1 merupakan Indeks Dst pada November 2014-April 2015 dan panel 2 merupakan hasil polarisasi sinyal geomagnetik pada November 2013-April 2014 dalam rentang frekuensi 0,05-0,02 $\mathrm{Hz}$. Waktu mula anomali polarisasi sinyal pada 23 Januari 2015 atau 4 hari sebelum gempa bumi 27 Januari 2015. Anomali ini ditunjukan dengan peningkatan pola polarisasi melebihi $\mu+2 \sigma$ sebelum gempa bumi terjadi yang terlihat pada Gambar 4.6 pada blok merah sebelum gempa 27 januari 2015. Dalam arti fisis penurunan harga Z/H menggambarkan bahwa batuan di bawah permukaan mengalami regangan batuan. Berdasarkan data Indeks Dst pada Gambar 4.3, saat anomali terjadi tidak terdapat adanya badai, hal ini berarti anomali yang terjadi merupakan anomali yang disebakan oleh gempa bumi 27 Januari 2015.

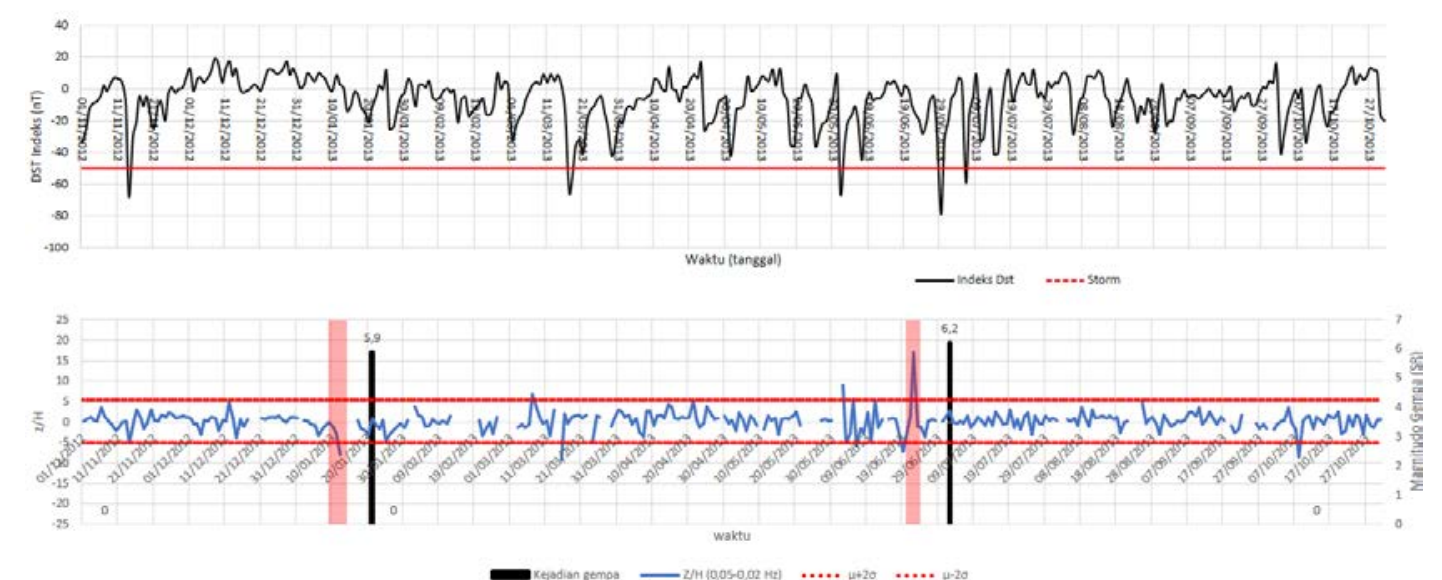

Gambar 1 : Indeks Dst Polarisasi sinyal geomagnet pada November 2012-Oktober 2013. Blok merah menunjukan adanya anomali polarisasi sebelum kejadian gempa bumi. 


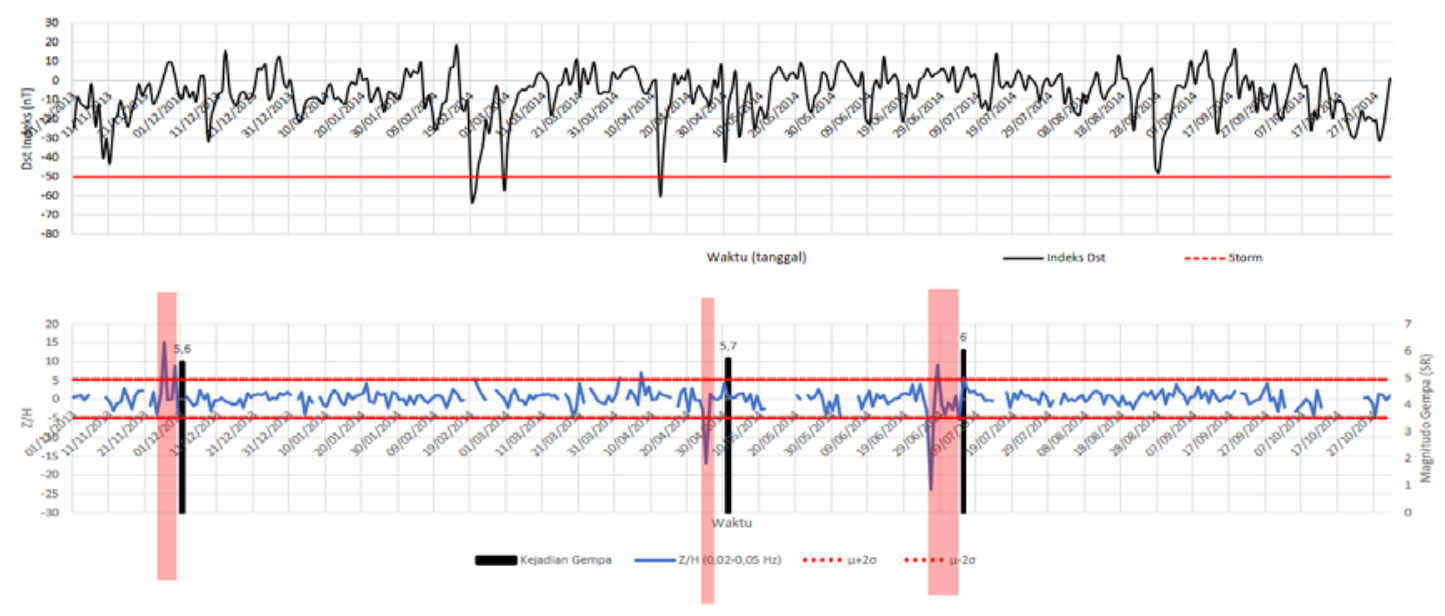

Gambar 2 : Indeks Polarisasi sinyal geomagnet pada November 2013-Oktober 2014. Blok merah menunjukan adanya anomali polarisasi sebelum kejadian gempa bumi.

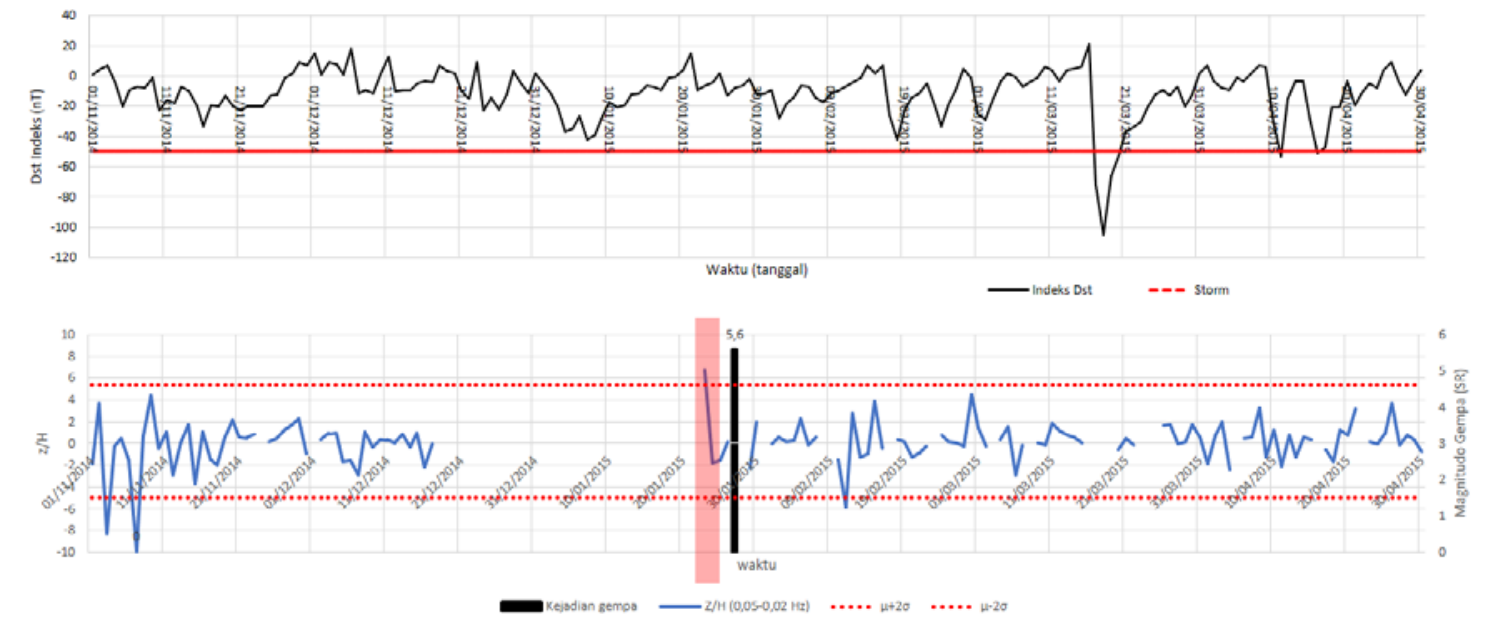

Gambar 3 : Indeks Polarisasi sinyal geomagnet pada November 2014-April 2015. Blok merah menunjukan adanya anomali polarisasi sebelum kejadian gempa bumi.

Berdasarkan uraian tersebut, penerapan prosedur polarisasi sinyal geomagnetik memperlihatkan respon anomali polarisasi sebelum terjadinya gempa bumi Pola anomali sinyal magnetik yang disebabkan oleh gempa bumi rata-rata terjadi kurang dari 30 hari sebelum kejadian gempa yang diuraikan pada Tabel 2. Hal ini sesuai dengan hasil investigas Hatori, dkk. (2004) bahwa metode polarisasi dapat mendeteksi anomali emisi ULF pada jangka pendek (short time). Sehingga hal ini dapat kita pahami bahwa untuk memprediksi terjadinya gempa bumi secara ideal masih sulit ddilakukan karena kondisi geologi dan tatanan tektonik yang berbeda-beda disetiap tempat. 
Tabel 2. Waktu mula anomali polarisasi sinyal magnetik sebelum terjadi gempa

\begin{tabular}{cccc}
\hline No & $\begin{array}{c}\text { Kaktu } \\
\text { Gejadian } \\
\text { Gempa }\end{array}$ & Magnitude & $\begin{array}{c}\text { Waktu Mula } \\
\text { Anomali } \\
\text { sebelum } \\
\text { gempa (hari) }\end{array}$ \\
\hline 1 & $21 / 01 / 2013$ & 5,9 & 9 \\
\hline 2 & $2 / 07 / 2013$ & 6,2 & 13 \\
\hline 3 & $01 / 12 / 2013$ & 5,6 & 5 \\
\hline 4 & $01 / 05 / 2014$ & 5,7 & 6 \\
\hline 5 & $05 / 07 / 2014$ & 6 & 9 \\
\hline 6 & $27 / 01 / 2015$ & 5,6 & 4 \\
\hline
\end{tabular}

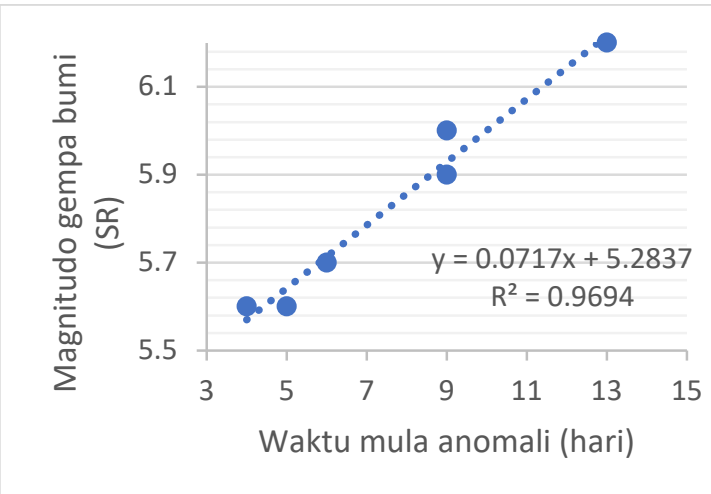

Gambar 4. pola rentang waktu anomali polarisasi sinyal terhadap magnitude gempa bumi di wilayah Aceh dan

\section{Sumatera Utara}

Hasil waktu anomali polarisasi sinyal geomagnetik pada spektrum $0,05-0,02 \mathrm{~Hz}$ kemudian dikorelasikan magnitude gempa bumi yang di investigasi. Hal ini diperlukan untuk mengetahui pola waktu anomali polarisasi sinyal terhadap kekuatan gempa. Hasilnya menunjukan bahwa pola waktu anomali akan semakin lama dengan bertambahnya magnitude gempa. Pola ini ditunjukan oleh grafik pada Gambar 4.

Secara fisis pola ini menunjukan bahwa waktu terjadinya anomali sangat bergantung dengan besarnya potensi gempa yang akan dihasilkan. Pola tersebut menggambarkan bahwa jika rentang waktu menunjukan waktu yang panjang maka potensi energi gempa yang dihasilkan akan lebih besar dibandingkan dengan rentang waktu yang pendek. Peningkatan rentang anomali akan menyebabkan peningatan energi gempa bumi. Berdasarkan penjelasan Uyeda dkk. (2009) dan Hattori dkk., (2006) yang menyatakan bahwa kemampuan pengamatan geomagnet di suatu observatorium yang dapat medeteksi anomali emisi sinyal geomagnet $<1$ bulan. Sehingga waktu maksimum terjadinya anomali adalah 30 hari.

Oleh karena itu, persamaan pada grafik tersebut merepresetasikan pola waktu anomali polarisasi sinyal geomagnetik $<10$ hari dapat berpotensi menghasilkan gempa $5<\mathrm{Mw}<6$, pola waktu anomali polarisasi 10-20 hari dapat berpotensi menghasilkan gempa $6<\mathrm{Mw}<6,7$, dan untuk pola waktu anomali polarisasi 2030 hari berpotensi menghasilkan $6,7<\mathrm{Mw}<9$. 


\section{Kesimpulan}

Pola waktu mula anomali polarisasi sebelum gempa bumi menunjukan rentang waktu yang lama akan menyebabkan potensi energi gempa yang dihasilkan akan lebih besar dibandingkan dengan rentang waktu yang pendek

\section{Referensi}

1. Hattori, K. (2004). ULF Geomagnetic Chages Associated with Large Earthquake. Terrestrial, Atmospheric and Oceanic Science, TAO, 15, 329360

2. Hatori, K., Serita, A., Yushino, C., Hayakawa, M., Isezaki. (2006). Singular Spectral Analysis and Principal Component analysis for Signal and principal component analysis for signal discrimination of ULF geomagnetic associated with 2000 Izu Izland Earthquake Swarm. Phys. Chem. Earth, 31, 281-291.

3. Nurdiyanto, B. (2011). Integration of Geophysical Parameter Observation in the Earthquake Predictability, JCM2011- Nopember, Proceedings of the 36th HAGI and 40th IAGI Annual Convention and Exhibition, Makasar.

4. Prattes, G., Schwingenschuh, K., Eichelberger, H., Magne, W., Boudjada, M., Stachel, M., Vellante, M., Villante, M., Wesztergom, V.,
Nenovski, P. (2011). Ultra Low Frequency (ULF) European Multi Stastion Mmagnetic Field Analysis before and during The 2009 Earthqauke at L'Aquila Regarding Regional Geotechnical Information. Natural Hazards Earth System Sciences, $\quad 11, \quad$ 1959-1968. doi:10.5194/nhess-11-1959-2011

5. Uyeda, S., dan Meguro, K. (2004). Earthquake prediction, seismic Hazard, and Vulnerability, 349-35.

6. Yumoto, K., S. Ikemoto, M.G. Cardinal, H. Hayakawa, K. Hattori, J.Y Liu, S. Saroso, M. Ruhimat, M. Husni, D.S. Widarto, E. Ramos, D. McNamara, R.E. Otadoy, G. Yumul, R. Ebora, dan N.Servdano. (2009). A new ULF wave analysis for Seismoelectromagnetic using CPMN/MAGDAS data. Physics and Chemistry of the Earth. 34(2009): 360366. 